\title{
ePortfolios for Assessment Purposes in the Foreign Language Classroom: A Project Outline
}

\author{
Shelley Hay \& Hongying Xu (La Crosse, Wisconsin/USA)
}

\section{Introduction}

According to a 2013 survey conducted by the EDUCAUSE Center for Analysis and Research, 54\% of students enrolled in United States higher education institutions reported working with ePortfolios in 2012 (Dahlstrom et al. 2013: 15). In academic settings, ePortfolios have not only continued to increase in popularity, but have shifted from primarily course-level to more frequent program-level adoption (Brown et al. 2012: 132). The "multifaceted nature" of ePortfolios allows them to simultaneously fulfill a variety of goals, and most institutions use them for multiple purposes, for example, showcasing student work, assessment, learning, or advising (Catalyst for Learning website).

Similar spheres of use are noted in the blog Defining "Portfolio": Four Ways of Seeing an ePortfolio (Batson 2015). According to the author, ePortfolios support student learning, institutional assessment, technology in education and current cultural and economic trends in society. In the context of learning, ePortfolios are used to engage students in inquiry and reflection of their own learning, as well as in the integration of their learning across different courses throughout their college career and their personal experiences outside the classroom. With regard to institutional assessment, ePortfolios are used to collect data of student learning so that institutions can track how well learning objectives are being met. Compared with other applications and technology often used on campuses, such as course management systems, ePortfolios give students more ownership of their work 
because they can, in some instances, grant selective access to their ePortfolios, as well as retain materials after graduation. And finally, within the sphere of culture and economy, ePortfolios support shifts toward a more personalized learning experience as well as one that prepares students for a rapidly and continuously changing workforce, specifically by collecting and certifying evidence from more active and problem-based learning experiences.

These benefits, especially the advantages associated with ePortfolio use for assessment purposes, have inspired this chapter. The first part provides an overview of ePortfolio scholarship in the United States, focusing on the general development in recent years, evidence-based research of ePortfolio effectiveness, and the study of ePortfolio use in the foreign language classroom. It is by no means an exhaustive literature review, but rather a summary of potential sources one may want to consult when implementing ePortfolios in a course or program. The second part of the chapter describes the ongoing plans to implement an ePortfolio requirement in two foreign language programs at the University of Wisconsin-La Crosse. It describes current assessment challenges, general implementation steps, and thoughts on how ePortfolios will be used to collect data and strengthen student learning in these programs.

\section{Literature review}

\subsection{General ePortfolio developments in U.S. higher education}

While ePortfolios are clearly "direct descendants of reflective print portfolios" occasionally used in writing and teacher education programs in the 1980s, there are a number of factors beyond the growth of the internet that supported the transition to electronic portfolios in the 1990s (Kahn 2014). For instance, there has been increased demand for direct evidence of student learning at the college, university, state and federal levels, as well as from accrediting associations. ePortfolios provide a venue for digital storage and organization of student work. Moreover, ePortfolios have the power to show authentic performances and competencies of student work through a variety of media: presentation slides, video clips, podcasts or other audio files, pictures, diagrams, etc. This gives ePortfolios a clear advantage over more traditional paper-based assessments. Naturally, electronic portfolios come with new challenges as well, such as the cost of purchasing and maintaining hardware and software, or the time it takes for instructors and students to become familiar with different platforms. Nevertheless, the continual shift toward adoption implies that many stakeholders believe the benefits of using ePortfolios outweigh the disadvantages.

Several projects in the 2000s paved the road for more widespread adoption of ePortfolios. In 2006, Jafari and Kaufman published the Handbook of Research on ePorffolios, a comprehensive reference and resource book devoted exclusively to the 
topic. It focuses on both theoretical aspects as well as the practical implementation of ePortfolios with supporting evidence from several case studies. The handbook covers the design, implementation, benefits, challenges and potential future uses of ePortfolios.

Relevant within the context of assessment, the Association of American Colleges \& Universities (AAC\&U) completed the VALUE (Valid Assessment of Learning in Undergraduate Education) Rubric Development Project in 2009.1 As part of the AAC\&U's LEAP (Liberal Education and America's Promise) Initiative, sixteen rubrics were created to measure Essential Student Learning Outcomes, such as Critical Thinking or Intercultural Knowledge and Competence. These rubrics have been widely adopted to assess student artifacts uploaded to ePortfolios.

The Association of Authentic, Experiential, and Evidence-Based Learning (AAEEBL) was established in 2009. It is a professional organization dedicated to promoting and supporting ePortfolio learning in higher education. Comprised of 125 member institutions and fifteen corporate partners, AAEEBL hosts an annual national conference, as well as various regional conferences, webinars, and publications.

Originally launched in 2011 and becoming an official publication of the AAC\&U in 2017, the International Journal of ePortfolio (IjeP) is a peer-reviewed, open access journal, which seeks "to encourage the study of practices and pedagogies associated with ePortfolio in educational settings" (IjeP website). Appearing twice a year, it publishes research into the benefits and effectiveness of ePortfolios in these educational settings, as well as specific case studies focused on student learning and assessment. It has become one of the most important databases for ePortfolio practitioners.

The Connect to Learning (C2L) project, a collaboration that began with 24 participating institutions in 2011, provides a venue for higher education institutions in the U.S. to share their experiences with ePortfolio initiatives. They have created the Catalyst for Learning Framework to support institutions interested in ePortfolio implementation, and generated a 2014 evidence-based report on ePortfolios titled "What Differences Can ePortfolio Make? A Field Report from the Connect to Learning Project" (Eynon et al. 2014). For strategies on the how to implement an ePortfolio initiative, High Impact ePortfolio Practice: A Catalyst for Student, Faculty, and Institutional Learning (Enyon \& Gambino 2017) draws on the C2L project as well.

In 2016, the AAC\&U added ePortfolios as the eleventh High-Impact Practice (HIP) to its original list of ten. As part of the aforementioned LEAP initiative, HIPs are often associated with improved student learning, retention rates, and graduation rates. Unique to the ePortfolio HIP, however, is its ability to potentially function as a kind of meta-HIP, one around which all other HIPs can be orga-

\footnotetext{
${ }^{1} \mathrm{~A}$ list of relevant abbreviation and acronym meanings is provided at the end of this chapter.
} 
nized. This idea is explored in the article "Reflective E-portfolios: One HIP to Rule Them All" (Hubert et al. 2015).

Yet more recently, the Field Guide to Eportfolio (Batson et al. 2017) was released, a publishing project which was produced as a collaboration between the organizations and practitioners most active in the ePortfolio field, including the AAC\&U, AAEEBL, IjeP, and the Electronic Portfolio Action and Communication (EPAC) Community of Practice. It highlights the concept of ePortfolio as an idea rather than mere product by exploring how the fields of situated cognition, high-impact practices and ePortfolio can be integrated instead of developing on their own in parallel.

\subsection{Evidence-based effectiveness of ePortfolios}

In the early stages of ePortfolio practice and research, little evidence was provided on the actual effectiveness of ePortfolios. Bryant and Chittum (2013) conducted a literature review based on 118 peer-reviewed journal articles on the research on ePortfolios from 1996 to 2012, the majority of which were published from 2008 to 2012. They found that $50(42 \%)$ of the articles were descriptive in nature, citing learning theories and data from other studies or describing individual experiences with ePortfolios as a program or institution. Fifty-eight studies $(49 \%$ out of the total sample) presented original data on the effectiveness of ePortfolios, however, the majority of these studies $(69 \%$ of those presenting original data) focused on students' feelings and opinions regarding ePortfolios. Only 18 studies (15\% out of total sample) presented data on student outcomes by using more valid and reliable measurements, including academic achievements and non-academic achievements such as motivation, reflective learning, critical thinking, integrative learning, and self-regulatory learning. That is to say, many studies relied heavily on indirect measures of assessment and student perception alone, while failing to incorporate direct measures of assessment into the research as well. Both are needed to provide a balanced and complete picture of ePortfolio effectiveness.

The previously mentioned 2014 C2L report has filled in some of the gaps identified in Bryan and Chittum's literature review. Compiling information from public and private institutions of varying sizes and exploring ePortfolio use at the course and program level, the report provides empirical evidence from participating campuses and demonstrates the effectiveness of ePortfolios in various ways: Improved student success as measured by grade point average, course completion rate, retention rate, and graduation rate; increased reflection, integration, and deep learning among students; and institutional changes towards a more learningcentered culture. Additional benefits of ePortfolio use have been found in more recent studies as well, for example, Using Eportfolios to Deepen Civic Engagement (O'Laughlin \& Serra 2016). As more institutions implement ePortfolios, we can expect an increase in evidence-based scholarship on the topic. 


\subsection{Use of ePortfolios in U.S. foreign language education}

As detailed in the previous section, a review of general ePortfolio literature indicates that ePortfolios can improve students' reflective (Morreale et al. 2017) and integrative learning (Reynolds \& Patton 2014), provide a means to showcase authentic student work, or function as a useful assessment tool (Catalyst for Learning website). It is not difficult to see how ePortfolios could be adopted to reinforce the five Cs of the World-Readiness Standards for Learning Languages (American Council on the Teaching of Foreign Languages [ACTFL] website):

- communication

- cultures

- connections

- comparisons

- $\quad$ communities

Students are supported in the development of communicative competence in the interpersonal, interpretive, and presentation modes; intercultural competence in regard to cultural products, practices and perspectives; making connections between language study and other disciplines; setting goals and reflecting on progress while becoming life-long learners; and interacting with people in various communities. A well-organized ePortfolio seems like an ideal tool to help foreign language learners achieve these learning goals, especially in terms of reflection and proficiency development awareness. Despite this natural fit, there has not been a significant amount of empirical research conducted in this particular area.

While there is a history of using paper portfolios in the field of U.S. teacher education training, it is more difficult to find studies which deal primarily with foreign language education. Combining the two areas, Firdyiwek and Scida (2014) describe the use of ePortfolios in a graduate-level pedagogy course: Teaching Foreign Languages. Most of the students in this class are teaching assistants (Tas) in foreign language classes with no previous classroom experience. The goal of the course is to familiarize these graduate students with pedagogical theories and principles, and more importantly, to give them opportunities to apply these principles in their daily teaching activities while encouraging self-reflection and critical thinking. The Tas engage in these reflective processes with the aid of an ePortfolio, for example, by sharing and commenting on teaching videos, organizing the information in the ePortfolio for review by the instructor, posting discussion questions for other students, completing an action research project, and adding reflective essays. Firdyiwek and Scida point out that the ePortfolio experiences of graduate student teaching assistants enrolled in the pedagogy course can be transferred to their own teaching in language courses. The Tas can encourage undergraduate language students to reflect on their learning and progress, to collaborate with their peers, and to create a learning community. 
Karsenti and Collin argue that use of ePortfolios in foreign language education is "generally associated with the notions of plurilingualism and self-regulated learning" (2010: 69). They propose that under an instructor's guidance, ePortfolios can be used for language learners to set goals for specific aspects of their language competency and to monitor how well they are achieving their goals. They suggest that students' ePortfolios can be organized around different competencies.

Young and Pettigrew (2012) report a redesign of their first- and second-year Spanish Program by changing formerly face-to-face courses into blended-learning experiences. Accordingly, they use ePortfolios as a platform for students to document their work and demonstrate their development of communicative and intercultural competence. Students are required to post samples of their online assignments in their ePortfolios, including podcasts, blogs, presentations, and selfassessment checklists. In this curricular redesign, ePortfolios are mainly used to showcase student work. Other ePortfolio functions such as peer review or integrative reflection of the learning process have not yet been used.

The platform that Young and Pettigrew used is LinguaFolio, an ePortfolio tool which allows students to collect evidence and demonstrate their competencies in a foreign language. This platform, the American equivalent to the European Language Portfolio (ELP), is maintained by the Center for Applied Second Language Studies at University of Oregon. It is structured within the framework of five competencies. Students can self-assess and submit evidence of their proficiency based on the NCSSFL (National Council for State Supervisors for Languages)ACTFL Can-Do Statements, as well as their intercultural experiences and reflections on their learning. The platform enables students and teachers to set goals and monitor their progress towards these goals. It also gives students opportunities to reflect on as well as gain more ownership of their learning. Student work submitted to LinguaFolio can be reviewed by instructors as well as peers.

\subsection{The literature in summary}

A review of the literature reveals an increase in the use of ePortfolios in different types of U.S. higher education institutions: from large research universities to small liberal arts colleges, from four-year universities to two-year community colleges. These ePortfolio initiatives often started at the course-level, but many of them have scaled up to become program- or even campus-wide requirements. Some institutions use ePortfolios primarily as an assessment tool, others use them as an add-on to facilitate integrative reflection and collaboration. Evidence from the campuses participating in the C2L project and other initiatives has contributed to the decision to list ePortfolios as an AAC\&U High-Impact Practice (Watson et al. 2016). HIPs, i.e., educational practices such as first-year seminars, learning communities, writing-intensive courses, or undergraduate research, have been repeatedly shown to improve overall student success. Being recognized as an official HIP may promote the adoption of ePortfolios in even more institutions. 
There is not a vast amount of literature on the use or effectiveness of ePortfolios in U.S. foreign language education, but the authors of this book chapter hope to contribute to the discussion, particularly in the realm of assessment, with their upcoming ePortfolio project.

\section{Future ePortfolio plans in Chinese Studies and German Studies at the University of Wisconsin - La Crosse}

The Department of Global Cultures and Languages at the University of Wisconsin-La Crosse is comprised of five distinct language programs which offer a variety of major, minor, and certificate options to the university's largely undergraduate student population. In addition to general majors, teacher education majors, and business concentration majors in French, German Studies, and Spanish, the department also offers a minor in Chinese Studies, a certificate in Russian Studies, and Hmong courses for heritage speakers. ${ }^{2}$ While individual programs largely determine their own course offerings, the department functions as a unified whole to maintain a certain degree of consistency across programs. One way in which GCL strives to work as a coherent unit is in the area of assessment.

\subsection{Overview of current GCL assessment}

Before the Fall 2012 semester, individual programs in the department assessed student learning outcomes at the course, program, and General Education levels independently. In the last five years, the department has made significant changes to our assessment process that have allowed us to determine common goals across language programs; become more efficient by sharing resources, results, and assessment strategies; and strengthened our identity as a single departmental unit. The most relevant changes have included:

1. The 2013 formation of a departmental Assessment Committee, comprised of at least one member of each language program. The committee proposes each academic year's assessment objectives, drafts assessment protocols and rubrics, and reviews collected data the end of each assessment cycle.

2. A regular focus on assessment at faculty meetings and retreats.

\footnotetext{
${ }^{2}$ Hmong Americans are an Asian ethnic group which began migrating to the US from countries such as Laos and Vietnam in the 1970s. The largest Hmong American populations in the US are in California, Minnesota, and Wisconsin.
} 
3. The 2015 revision and adoption of a single set of student learning outcomes for all programs in GCL. By agreeing on shared SLOs, faculty can more easily identify common strengths and weaknesses, as well as compare data and adopt successful pedagogical practices that colleagues in other programs use to achieve particular outcomes. This kind of team work and cross-program engagement is especially useful for our smaller language programs.

4. Funded opportunities for assessment-related training, e.g., attendance at conferences and workshops related to various aspects of assessment.

By coordinating our assessment efforts in these ways, faculty are given opportunities to collaborate with one another while still maintaining the autonomy individual programs require to meet the varying needs of students.

The departmental student learning outcomes focus on oral and written proficiency in the target language, the development of cultural knowledge and skills, and critical thinking. They parallel certain university General Education outcomes, as well as what many instructors have listed as specific course learning outcomes. This coordination of outcomes on various levels is crucial to the success of the department's assessment plan. The overarching philosophy of the GCL Assessment Committee is that we should use existing course-embedded assignments whenever possible to guide the development of program and General Education assessment. In other words, the same assessment measure may provide courselevel, program-level, and General Education-level data. This increases faculty participation by minimizing the amount additional work required of busy colleagues. Moreover, assessment protocols and measures are coordinated loosely enough - more in structure and procedure than content - to allow individual programs to retain a large degree of freedom. Each instructor determines the exact subject-matter of an assessment measure, and programs set independent benchmarks.

Many course- and program-level benchmarks are determined using the ACTFL proficiency guidelines. For interested instructors and students, these can be assigned CEFR (Common European Framework of Reference for Languages) ratings using an online conversion chart accessible through the ACTFL website. Each program determines the oral and proficiency level they would like their majors and minors to attain by the end of the program.

Despite the recent improvements to the department's assessment process, programs still face certain assessment challenges. First and foremost, collecting data on each student learning outcome at the end of a student's progress through some GCL language programs can be difficult because many programs are unable to sequence courses in the curricula. After the beginning and intermediate levels (100- and 200-level courses), advanced language learners often take whatever upper-level course is offered in a given semester. In particular, small language programs that only employ one or two instructors cannot offer more than one or 
two 300- or 400-level courses a semester. This means that all majors and minors, regardless of proficiency level, receive instruction together. Furthermore, the last course students take in the program - the ideal moment in a student's academic career to assess outcomes - essentially depends on which course happens to be offered the semester before they graduate. These unavoidable curriculum circumstances clearly complicate our data collection progress.

Currently, the Assessment Committee attempts to address this issue by asking each student enrolled in an upper-level course to complete a background questionnaire before conducting the semester's assessment. The questionnaire gathers information on the courses students have taken within the program, the order in which they completed their courses, whether the student has studied abroad yet, how many study abroad credits a student has transferred back, etc. Students are then put into categories based on the number of credits completed ( $0-10$ credits, 11-20 credits, and $21-33$ credits). ${ }^{3}$ Each category has a distinct linguistic proficiency benchmark. For example, a German Studies student with 9 credits of upper-level coursework completed is expected to perform at a minimum at an IntermediateLow oral and written proficiency level on the ACTFL scale, while a German Studies student with 30 credits should score at least at an Intermediate-High level. If some students do not achieve the benchmark, the collected questionnaire data can be analyzed and may help instructors determine gaps in the curriculum. Nevertheless, this practice only leads to assessment data "snapshots". We do not assess all majors and minors at the end of the program, but rather an uncontrolled sample. We would naturally like to improve this process.

\section{2 ePortfolios UWL's Language Programs}

The GCL Assessment Committee has concluded that implementing an electronic portfolio requirement for language majors, minors, and certificate seekers could help us address this assessment data collection issue. If students in language programs are encouraged to upload a variety of assignments to an ePortfolio each semester in order to graduate, faculty would have the ability to better target assessment of student learning outcomes. Instructors could easily determine the last course a student takes in the program before graduating, regardless of whether the student is a major or minor, and use the uploaded assignments from the course as the material for the assessment being conducted at that moment. Similarly, instructors could select assignments from earlier semesters to measure proficiency gains over time. As previously mentioned, many current ePortfolios allow users to not only add writing samples, but also audio and visual files, so regardless of the kinds of activities assigned in class or the outcome being assessed, ePortfolios could help language learners keep an ongoing record of coursework.

\footnotetext{
${ }^{3}$ Generally, one credit at a US institution is comprised of one contact hour in class and two additional preparation hours outside of class. This comes to roughly 45 hours of work per credit a semester.
} 
Maintaining a record of coursework and tracking student progress through the program could have benefits beyond the collection of direct assessment measure data. For example, it would provide a venue for GCL faculty to create and implement more indirect measures of assessment, such as exit surveys, evaluations of instruction, student self-evaluation of progress, etc. The department's current vision of the ePortfolio structure would also provide a platform to help increase student reflection on, engagement with, and motivation for the language learning process. There may be additional benefits that only come to light once we begin designing and implementing the use of ePortfolios in our individual language programs.

The current stage of ePortfolio design was preceded by various research steps to determine what kind of ePortfolio platform would best serve our needs, as well as to create a realistic implementation plan and timeline. The current project began during the Spring 2016 semester when two members of the GCL Assessment Committee at that time, Shelley Hay (German Studies) and Heather Linville (TESOL - Teaching English to Speakers of Other Languages) received a UWL Program Assessment Initiative Grant. The grant recipients consulted with other UWL departments and colleges using ePortfolios and explored various platform options. In the end, it was decided that Taskstream by Watermark would best fulfill the department's needs: Taskstream's AMS (Accountability Management Software) was already being used at UWL for General Education assessment; it was in the process of being adapted for program assessment as well; it has a LAT (Learning Achievement Tools) ePortfolio section that directly connects to the AMS already being used; all students enrolled in the university currently have access to the software; and Taskstream representatives were easy to contact and willing to work with the department to achieve our ePortfolio and assessment goals. ${ }^{4}$

The following academic semesters were spent brainstorming, becoming more familiar with published research on the subject, and attending ePortfolio panels at various conferences to learn more about the successes and challenges associated with ePortfolio use in the foreign language classroom. After deciding that German Studies and Chinese Studies would be the programs best suited to pilot ePortfolios for assessment purposes, the authors of this chapter began collaborating on the actual design and implementation of the project. ${ }^{5} \mathrm{~A}$ two-year plan which maps out individual stages of design and implementation was created in August 2017.

\footnotetext{
${ }^{4}$ These are a few of the reasons that the authors opted to use Taskstream by Watermark rather than a platform such as Linguafolio.

${ }^{5}$ German Studies and Chinese Studies were chosen for a variety of reasons: The section heads $\mathrm{Xu}$ and Hay) for both programs have been involved in GCL assessment for the past five years and are highly invested in the process; the programs are relatively small and manageable; both programs offer a variety of courses at every level of instruction; German Studies offers three majors (including teacher education training) and a minor. In other words, the programs are structured, small, and flexible. It will be possible to implement an ePortfolio and quickly make changes where necessary.
} 
Timeline for implementation of ePortfolios in German Studies and Chinese Studies:

- Fall 2017: Brainstorming and more research; outline of project submitted for publication to "Edited Volume on Portfolios in the Foreign Language Classroom."

- Winter break 2018: Begin creating ePortfolio template in Taskstream.

- Spring 2018: Present at UWL Assessment Commons (January) and Central States Conference on the Teaching of Foreign Languages (March) in order to share progress of ePortfolio project, attend ePortfolio panels to learn more, and receive feedback; finish ePortfolio template design with feedback from colleagues and students.

- Fall 2018: Pilot ePortfolio in one course in German Studies and one course in Chinese Studies; collect data; make modifications.

- Spring 2019: Pilot in all courses in German Studies and Chinese Studies; present to colleagues in GCL at the end of the semester; implement assessment plan.

- Summer 2019: Make changes based on preliminary assessment of ePortfolio; mentor other language programs who may want to implement ePortfolios; compile results for publication.

As one can see, at the time this chapter was written, the authors were beginning to create an ePortfolio template for German Studies and Chinese Studies courses.

\section{3 ePortfolio structure}

Our current vision of the German Studies and Chinese Studies ePortfolios would require students to upload assignments in every course, before they have possibly declared a major or minor. In other words, even first- and second-semester students would store, reflect on, and revisit at various times course material in Taskstream. These assignments and reflective essays could be used for program review and General Education assessment, as well as provide a digital space for students to experiment creatively and take ownership of their academic development. We are creating program templates that will guide students in the creation of their individual ePortfolios. Each program would have certain elements in common.

1. Every course would clearly indicate which student learning outcomes are targeted at that level. It would also indicate specific course assignments that should be uploaded in connection with each SLO. For example, GER 201 and CHI 201 courses focus on the first three departmental student learning outcomes: oral proficiency, written proficiency, and cultural competency. Each student would be instructed to upload an audio recording of his or her oral exam, a copy of an 
in-class writing assignment, and a cultural artifact such as a picture board depicting, comparing, and analyzing German and American customs in different venues. These are course-embedded assignments that are conducted each time the course is taught. Students frequently work with course management systems, so submitting the assignments and reflections through their ePortfolios should not increase student or faculty workloads.

2. Every course would also provide the assessment protocols, rubrics, and individual results to students. Providing language learners with this information not only helps ease anxiety associated with summative assessments, but it also makes the course goals more transparent and allows students to track their own progress over time.

3. As previously mentioned, best ePortfolio practices indicate that students benefit when there are opportunities to reflect on their assignments and learning. These will be provided through the ePortfolio in various ways.

First, upper-level students will be encouraged to ruminate on what they have learned each semester by commenting on how they believe designated course assignments helped them achieve specific student learning outcomes. For example, GER 321 students (German Civilization from 1989-today) work together over the course of the semester to create poster presentations on topics relevant to contemporary German society, which they present to their peers at the end of the semester. If recorded, the presentations as well as photos of the posters can be uploaded to the ePortfolio for assessment. The reflection assignment in English in lower-level courses, in the target language in upper-level courses - would ask students to think about how the poster presentation projects helped them deepen their knowledge and understanding of German society. Second, all courses would include a levelappropriate copy of the NCSSFL-ACTFL Can-Do statement checklists - both the language proficiency as well as the newer intercultural competencies statements. Students would mark the tasks that they are comfortable completing at the beginning of the semester, and then mark tasks they have added to their repertoire by the end of the semester. This self-assessment comparison could help address a motivation issue that frequently occurs with language learners at the Intermediate proficiency levels. Students can spend multiple semesters at the Intermediate-Mid range, and they may at times feel discouraged because they do not believe that they are making enough progress in the language. Marking off new skills through the Can-Do statement checklists, however, will help students track language gains even when they progress more slowly through the official proficiency levels. 
4. If possible, we would like to work with Taskstream to allow for some sort of export of ePortfolio materials after students graduate. This could allow them to use certain assignments as evidence of their language abilities when applying for graduate school or employment. We may even be able to add general information to the ePortfolio about various soft skills that are developed when completing one of our language programs, e.g., leadership, problem-solving, or teamwork skills. In other words, we believe that maintaining a record of coursework and reflection throughout the course of a student's progress through our programs can help support them in their academic and career endeavors after leaving UWL.

Naturally, we want to maintain a degree of flexibility and adaptability while designing and implementing our pilot ePortfolio requirement in the Chinese Studies and German Studies programs. Some of the plans may change during the design-stage based on limitations encountered with the software. Some may change after implementation as we conduct direct and indirect assessments of the ePortfolio requirement, e.g., by surveying German Studies and Chinese Studies students before and after implementation, by comparing pre- and post-implementation oral and written proficiency data, and by possibly employing students in other GCL programs as informal control groups during the process. Once complete, we will report back to the rest of the Department of Global Cultures and Languages and consider whether full-scale adoption of ePortfolios in all language programs would be beneficial. We also plan to publish our findings once we have collected and analyzed our data. 


\section{Abbreviations and acronyms}

AAC\&U: Association of American Colleges \& Universities

AAEEBL: Association of Authentic, Experiential and Evidence-Based Learning

ACTFL: American Council on the Teaching of Foreign Languages

AMS: Accountability Management Software

C2L (project): Connect to Learning

CEFR: Common European Framework of Reference for Languages

ELP: European Language Portfolio

EPAC: Electronic Portfolio Action and Communication

GCL: Department of Global Cultures and Languages

HIP: High-Impact Practice

IjeP: International Journal of ePortfolio

LAT: Learning Achievement Tools

LEAP (initiative) Liberal Education and America's Promise

NCSSFL: National Council for State Supervisors for Languages

SLO: Student Learning Outcome

TA: Teaching Assistant

TESOL: Teaching English to Speakers of Other Languages

UWL: University of Wisconsin - La Crosse

VALUE (rubric): Valid Assessment of Learning in Undergraduate Education

\section{References}

Batson, Tobias (2015): Defining "ePortfolio": Four Ways of Seeing an ePortfolio (Blog). http:/ / aaeebl.site-ym.com/blogpost/1008436/211326/Defining-ePortfolioFour-Ways-of-Seeing-an-ePortfolio [04.12.2017].

Batson, Trent; Coleman, Kathryn S.; Chen, Helen L.; Watson, C. Edward; Rhodes, Terrel L.; Harver, Andrew (eds.) (2017): Field Guide to Eportfolio. Washington, D.C.: Association of American Colleges and Universities.

Brown, Gary; Chen, Helen L.; Gordon, Aifang (2012): The annual AAEEBL survey at two: Looking back and looking ahead. In: International Journal of ePortfolio 2/2, 129-138. http:/ /www.theijep.com/past_2_2.cfm [26.06.2019].

Bryant, Lauren H; Chittum, Jessica R. (2013): ePortfolio effectiveness: A(n illfated) search for empirical support. In: International Journal of ePortfolio 3/2, 189-198. http://www.theijep.com/past_3_2.cfm [26.06.2019].

Dahlstrom, Eden; Walker, J.D.; Dziuban, Charles (2013): ECAR Study of Undergraduate Students and Information Technology (Research Report). Louisville, CO: EDUCAUSE Center for Analysis and Research. https://library.educause.edu/ /media/files/library/2013/9/ers1302-pdf.pdf?la=en [26.06.2019]. 
Eynon, Bret; Gambino, Lauren M. (2017): High Impact ePortfolio Practice: A Catalyst for Student, Faculty, and Institutional Learning. Sterling, VA: Stylus.

Eynon, Bret ; Gambino, Lauren M. ; Török, Judit (2014): What difference can ePortfolio make? A field report from the Connect to Learning Project. In: International Journal of ePortfolio 4/1, 95-114. http://theijep.com/past_4_1.cfm [26.06.2019].

Firdyiwek, Yitna; Scida, Emily E. (2014): Reflective course design: An interplay between pedagogy and technology in a language teacher education course. In: International Journal of ePortfolio 4/2, 115-131. http://theijep.com/past_4_2.cfm [26.06.2019].

Hubert, David; Pickavance, Jason; Hyberger, Amanda (2015): Reflective Eportfolios: One HIP to rule them all? In: PeerReview 17/4. https://www. aacu.org/peerreview/2015/fall/Hubert [25.05.2019].

Jafari, Ali; Kaufman, Catherine (eds.) (2006): Handbook of Research on ePortfolios. Hershey, PA: Idea Group Reference.

Kahn, Susan (2014): E-Portfolios: A look at where we've been, where we are now, and where we're (possibly) going. In: PeerReview 16/1. https://www.aacu.org/ publications-research/periodicals/e-portfolios-look-where-weve-been-wherewe-are-now-and-where-were [26.06.2019].

Karsenti, Thierry; Collin, Simon (2010): The eportfolio: How can it be used in French as a second language teaching and learning? In: International Journal of Technologies in Higher Education 7/1, 67-75.

Morreale, Cathleen; Van Zile-Tamsen, Carol; Emerson, Cheryl A.; Herzog, Matthew (2017): Thinking skills by design: Using a Capstone ePortfolio to promote reflection, critical thinking, and curriculum integration. In: International Journal of ePortfolio 7/1, 13-28.

O'Laughlin, Nancy; Serra, Susan T. (2016): Using eportfolios to deepen civic engagement. In: PeerReview 18/3. https://www.aacu.org/peerreview/2016/ summer/olaughlin [26.06.2019].

Reynolds, Candyce; Patton, Judith (2014): Leveraging the ePortfolio for Integrative Learning: A Faculty Guide to Classroom Practices for Transforming Student Learning. Sterling, VA: Stylus.

Watson, C. Edward; Kuh, George D.; Rhodes, Terrel; Light, Tracy Penny; Chen, Helen L. (2016): ePortfolios: The eleventh high impact practice (Editorial). In: International Journal of ePortfolio 6/2, 65-69. http://theijep.com/past_6_2.cfm [26.06.2019]. 
Young, Dolly Jesusita; Pettigrew, Jason (2012): Blended learning in large multisection foreign language programs: An opportunity for reflecting on course content, pedagogy, learning outcomes, and assessment issues. In:

Rubio, Fernando; Thoms, Joshua J.; Bourns, Stacey Katz (eds.): AAUSC 2012 Volume - Hybrid Language Teaching and Learning: Exploring Theoretical, Pedagogical and Curricular Issues. Boston, MA: Heinle.

\section{Websites referenced}

AAEEBL - https://aaeebl.org/about/[19.07.2019].

ACTFL Can-Do Statements - https:/ /www.actfl.org/publications/guidelines-andmanuals/ncssfl-actfl-can-do-statements [26.06.2019].

ACTFL-CEFR Conversion - https://www.actfl.org/publications/additional-re sources/assigning-cefr-ratings-actfl-assessments [26.06.2019].

ACTFL World Readiness Standards for Learning Languages https://www.actfl.org/sites/default/files/publications/standards/WorldReadinessStandardsforLearningLanguages.pdf [26.06.2019].

Catalyst for Learning: ePortfolio Resources and Research - http:/ /c2l.mcnrc.org/ this-site/\#what-is-an-eportfolio [26.06.2019].

International Journal of ePortfolio - http://theijep.com/about.html [26.06.2019].

Linguafolio - https://casls.uoregon.edu/classroom-resources/linguafolio-onlineeportfolio/ [26.06.2019]. 